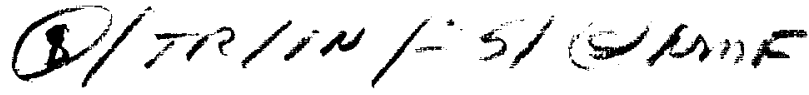

\section{Appendix F:}

Lin, K.-C. and Faeth, G.M. (1999) "Shapes of Nonbuoyant Round Luminous Laminar Jet Diffusion Flames in Coflowing Air," AIAA Journal 37, 759-765. 


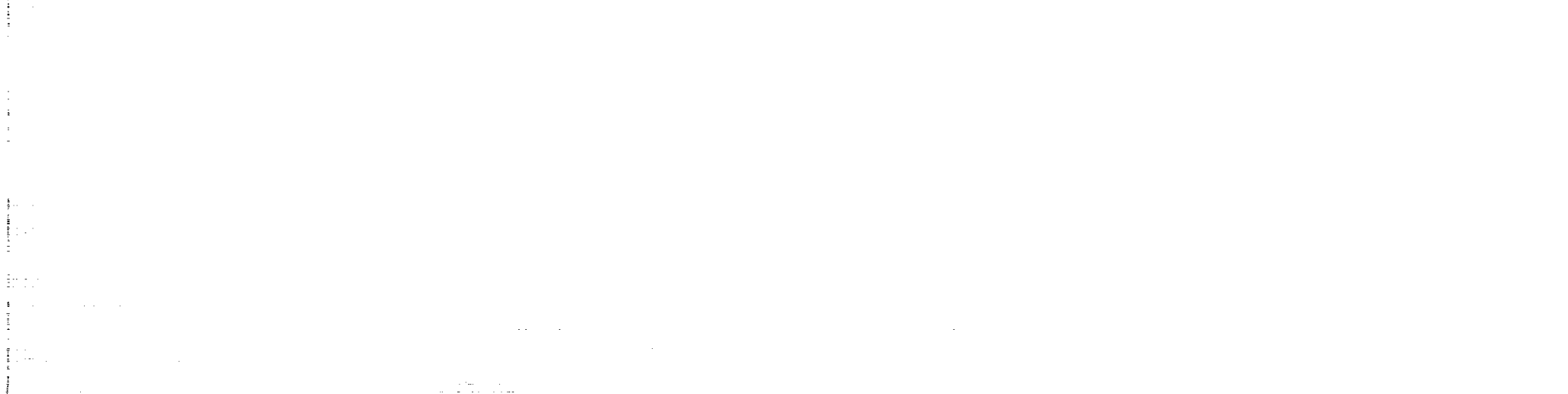

1
$\vdots$
$\vdots$
$\vdots$
$\vdots$
$\vdots$
$\vdots$
1

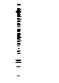


AIAA JOURNAL

Vol. 37. No. 6, June 1999

\title{
Shapes of Nonbuoyant Round Luminous Laminar-Jet Diffusion Flames in Coflowing Air
}

\author{
K.-C. Lin ${ }^{*}$ and G. M. Faeth ${ }^{\dagger}$ \\ University of Michigan, Ann Arbor, Michigan 48109-2140
}

\begin{abstract}
The shapes (luminons flame boundaries) of steady nonbuoyant round baminous bydrocarbon-fueled laminar-jet The shapes (luminous flame boundaries) of steady dosboth expertmentally and theoretically. Flame shapes were diffusion taros burning in cohowing alr were stodied boch expe in order to minimize the effects of buoyancy. Test measured from photographs of flames butning at low pressures in order to minimize the efrects of buayer. Test conditions involved acetylene-, propylene- and 1,3-butadiene-fueled fiames baving initiai reactant lemperatores of $300 \mathrm{~K}$, ambient pressures of $19-50 \mathrm{kPa}$, jetexit Reynolds numbers of 18-121, and initial tirftuel veloctiy ratios of 0.22-32.45 to yield Juminous flame lengths of 21-108 $\mathrm{mm}$. The present flames were dose to the laminar swolce of 0.22-32.45 to yield luminous flame lenghs of point but were not soot emitting. Simple expressions to extimate he shapes of al. (Mahalingam, S, Ferziger, J. H, tames in coffow were found by extending an eartier analysis of Maholingum et al. (Mahalingam, S, Ferziger, J. F, and Cantwell, B. J. "Self-Similar Difiusion Flames," Combustion and Flame, WoL. 22, No. 2, 19s, Pp. 231-234).

These formulas provided a good correlation of present measurements except
\end{abstract}

Nomenclature

$C_{f} \quad=$ empirical flame length facto

$C_{f} \quad=$ mass diffusivity

d $\quad$ jel-exit diameter

$F r_{g}, F r_{j}=$ air and fuel stream Froude numbers, $u_{a, e}^{2} /\left(2 g L_{f}\right)$ and $u_{f . e}^{2} /\left(2 g L_{f}\right)$

$f=$ mixture fraction

= acceleration of gravity

= distance from jet exit to luminous flame tip

$=$ distance from jet exit to vinual origin

= buster mass flow rate

= pressure

$=$ jet Reynolds number, $4 \dot{m} /(\pi d \mu)$

$=$ radial distance

$=$ Schmid number, $v / D$

$=$ streamwise velocity

= streamwise velocity defect: Eq. (1)

$=$ luminous flame diameter

$=$ luminous flame diameter at $\zeta=\frac{1}{2}$

= streamwise distance

$=$ mass fraction of fuel

$=$ mass fraction of oxygen

$=$ stoichiometric mixture fraction

= normalized streamwise distance; Eq. (12)

$=$ dimensionless radial distance: Eq. (6)

$=$ dynamic viscosity

$=$ kinematic viscosity

$=$ density

$=$ standard deviation of parameler $i$

Subscripls

a $\quad=$ airstream property

$f \quad=$ fuel-stream property

=burner exil-plane condition

Introduction

AMINAR nonpremixed (diffusion) flames are of interest because they provide model flame systems that are fat more

Received Aug. 20, 1998; revision received Dee. I5, 1998; accepted for Received Aug. 20, 1998; revision 1999 by the American Institure of Aeronautics and Astronautics. Inc. All rights reserved.

Research Associale, Department of Aerospece Engineering; currently Research Scientist. Taitech. Inc., Wright-Patterson Air Force Base, $O H$ 45433-0630.

A. B. Modine Professor, Department of Aerospace Engineering. Fellow ALA. tractable for analysis and experiments than more practical turbulent diffusion flames. Certainly understanding flame processes within laminar-jet diffusion flames must precede understanding these processes in more complex turbulent diffusion flames. In addition, many properties of laminar-jet diffusion fiames are directly relevant to turbulent diffusion flames using laminar flamelet concepts.' Laminarjet diffusion flame shapes (luminous flame boundaries) have been of jet difusion interest since the classical study of Burke and Schumann ${ }^{2}$ because they are a simple nonintrusive measurement that is convenient for evaluating flame-structure predictions. Motivated by these observations, the shapes of laminar diffusion flames were considered during the present investigation.

Nonbuoyant flames were emphasized during the present investigation to simplify interpretation and analysis of the measurements and increase the relevance of the results because most practical and increase the relevance of the results because most practical observing flames having large flow velocities at small pressures. Present methods were based on the study of the shapes of nonbuoy. Prend aminar-jet diffusion flames in still air due to Lin et al." ant round laminar-jet diffusion flames in still air due to Lin et al." predictions of the flame shapes reported by Uban et al. ${ }^{7}$ and Sunderland et al ${ }^{3.9}$ The objective of the present study was to extend Ref. 4 to consider the shapes of nonbuoyant round laminar-jet diffusion flames in coflowing air, prompted by the widespread use of this configuration to study the structure and soot formation processes of laminar diffusion flames (see Refs. 10-19 and references cited therein). Similar to Ref. 4, a way to correlate flame-shape results was sought, convenient for use by others, based on simplified analysis of nonbuoyant laminar coflowing jet diffusion flames.

Most earlier studies of the shapes of nonburoyant laminar-jet diffusion flames considered round hydrocarbon-fueled flames burning in still gases (generally air) (see Refs. 4-8, 20-33, and references cited therein). The results of these studies have raised several concerns: what conditions are needed to minimize effects of buoyancy when observations of nonbuoyant flames are sought at normal gravity, what is the effect of transient flame development on flameshape measurements when nonbuoyant conditions are provided by ground-based facilities where available test times are limited, and what is the effect of soot luminosity on the flame-shape measuremenis of hydrocarbon-fueled flames?" With respect to minimizing effects of buoyancy at normal gravity, experiments at low pressures ${ }^{3}$ and with very large flow velocities ${ }^{33}$ have proven to be effective tactics that will be exploited during the present study. Transient flame development effects have been problematical using groundbased low-gravity facilities due to the limited test times of drop towers $24-27$ and the flight-path disturbances of aireraft facilities. ${ }^{-9}$ Recent measurements from long-term low-gravity tests in space? 
and drop-lower tests at reduced pressures, however, have minimized transient flame development problems and yielded result that could be correlated by simplified theories as mentioned eartier.

Effects of soot luminosity on the shapes of hydrocarbon-fueled laminar-jet diffusion flames in still air are more problematical than effects of buoyancy and transient flame development. The luminosity of hydrocarton-fueled flames is caused mainly by glowing soot particles; therefore, the relationships berween luminous flame dimensions and the location of the flame sheet (where the local mix pre fraction is stoichiometic) are the main issues because the latter is generally associated with predictions of laminar flame shapes. Past measurements of the structure and soot properties of weakly buoyant and buoyant round laminar-jet diffusion fiames burning in still or slowly moving air indicate that luminous/stoichiometric fiame-length ratios are in the range 0.9-1.8, with the largest values observed as the laminar smoke point (the condition where the flame first begins to emit soot) is approached $9,12-16$ This behavio occurs because soot oxidation begins at slightly fuel-rich condition and can continue in the fuel-lean region for a time before the soot is either consumed (for non-soot-emitting or nonsooting flames) or the soot oxidation reactions are quenched (for s00t-emitting or sooting flames), with luminous fame lengths varying accordingly.? Finally, recent measurements of nonbuoyant laminar-jet diffusion flames in still air show that luminous flame lengths near laminar smoke-point conditions are roughly twice as long as those of sootfree (blue) flames at comparable conditions. ${ }^{4.8}$ Forunately, flame shapes at these two limiting conditions could still be correlated effectively based on the simplified Spalding analysis, after defining an empirical factor to represent effects of soot luminosity. Such empiricism is not desirable. but it is unavoidable at the present time because of limited understanding about soot reaction processes.

Even though the classic study of Burke and Schuman ${ }^{2}$ addressed the shapes of laminar coflowing jet diffusion flames (for the limiting condition where initial fuel and oxidant velocities were the same), there has been relatively little subsequent consideration of this problem. Exceptions include the theoretical studies of Williams ${ }^{34}$ and Mahalingam et al. ${ }^{35}$ which extended the Burke and Schumann ${ }^{2}$ analysis to treat flames where the outer coflowing stream was unbounded. During the present study, the simple self-similar analysis of Mahalingam et a. ${ }^{33}$ was further developed to provide a theoretical basis for correlating the shapes of nonbuoyant laminar-jet diffusion flames in coflowing air, analogous to the use of the simplified analysis of Spalding ${ }^{3}$ to provide a theoretical basis for correlating the shape of nonbuoyant laminar-jet diffusion flames in still air by $L$ in shape

The preceding discussion suggests that significant progress has been made conceming the shapes of the hydrocarbon-fueled laminar-jet diffusion flames in still air but that corresponding information for flames in coflowing air is very limited in spice of the importance of this configuration for studies of soot processes in laminar-jet diffusion flames. With this status in mind, the present investigation considered nonburoyant round luminous laminar-jet difvestigation considered nonburoyant round luminous laminar-jer dif-
fusion flames in coflowing air with the following specific objectives:

1) Measure the shapes (luminous fame boundaries) and associared properties such as laminar flame lengths and diameters for various fuel types, collow velocities, jel-xit how rates and ambient various fuet

2) Compare present measurements with earlier findings for similar flames in still aif, c.g. the flames observed in Ref. 4, to help quantify effects of coflow on flame-shape properties.

3) Exploit the new measurements to develop a correlation for the shapes of coflowing laminar-jet diffusion flames, convenient for use by others, by extending the earlier analysis of Burke and Schumann? by others, by extending the earlier
flames due to Mahalingam et al. ${ }^{35}$

Present observations were limited to sook-containing acetylene-, propylene- and 1,3-butadiene-fueled laminar-jet diffusion flams buming in coflowing air. Similar to Ref. 4, the measurements were limited to conditions near the laminar smoke point except for some preliminary observations to study the effect of approach to the lantinar smoke point on flame shapes.

The following discussion begins with descriptions of experimental and theoretical methods. Results are then considered, treating flame appearance, luminous flame lengths, luminous flame diameters, and luminous flame shapes, in tum. Major conclusions are summarized at the end of the paper.

\section{Experimental Methods}

Experimental methods will be described only briefly (see Refs. 17-19 for more details). Effects of buoyancy were minimized by observing flames at relatively small pressures ( $\leq 50 \mathrm{kPa}$ ) with either relatively large coflow velocities (air/fuel velocity ratios up to 32.45) or relatively large source Froude numbers when coflow velocities were small. The bumer was placed within a windowed cylindrical chamber and directed verically upward along its axis. The bumer was a coaxial-tube arrangement with the fuel flowing from the inner pon (6-mm inside diameter with the tube wall tapered to provide a negligible thickness at the tube exit) and air flowing from a concentric outer port (60-mm inside diameter). The inner port had sufficient length to provide fully developed laminar pipe flow at the bumet exit. The outer port had several layers of beads and screens to provide a uniform velocity flow at the burner exit. Flame lengths were limited so that test conditions approximated flames in a uniform air coflow based on laser velocimetry measurements of flow velocity distributions. ${ }^{17}, 19$ The windowed chamber had a diameter of 300 $\mathrm{mm}$ and a length of $1200 \mathrm{~mm}$. Optical access was provided by two pairs of opposing windows having diameters of $100 \mathrm{~mm}$ and centered on a horizontal plane located $500 \mathrm{~mm}$ above the base of the windowed chamber. The flames were positioned so that their full lengths could be observed and photographed through the windows.

Fuel was supplied to the inner port from commercial gas cylinders. Fuel flow rates were controlled and metered with critical flow orifices in conjunction with pressure regulators with this system calibrated with wet-test meters. Air was supplied from the room using critical flow orifices to control and meter air-how raxes. The exhaust products passed through a porous plate into a plenum chamber at the top of the windowed chamber to provide uniform flow conditions in the vicinity of the test flame. After dilution with air to reduce flow temperatures, the exhaust flow was removed using the laboratory vacuum pump system. The fames were ignited by a bot wire that could be manually moved out of the flowfield once flame stabilization was complete.

Dark field photographs of the fiames were obtained using a 35-mm reflex camer. The photographs were subsequently printed using a $100 \times 125 \mathrm{~mm}$ film format. The fiames were measured directly from these prints, using photographs of objects of known size to calibrate vertical and horizontal distances on the prints. Experimental uncertainties ( $95 \%$ confidence) of luminous flame diameters and lengths were less than 2 and $5 \%$, respectively.

Present test conditions are summarized in Table 1. Gas purities were greater than $99 \%$ for propylene and 1,3-butadiene but were only roughly $98 \%$ for acetylene due to contamination by acetone that is present in commercial acetylene gas cylinders for safety purposes. The effeet of the acetone was evaluated by comparing observations with and without acetone vapor present, using the acetone purification system described by Hamins et al. ${ }^{36}$ to create the acetone-free fuel stream. The effect of acetone on luminous flame shapes (and laminar smoke-poin flame lengths ${ }^{17.19}$ ) was small cormpared with experimental uncertainties. Present test conditions included reactan

Table 1 Sumanary of test condidease

\begin{tabular}{|c|c|c|c|}
\hline Paranicter & Acetylene & Propylene & 1,3-Butediene \\
\hline 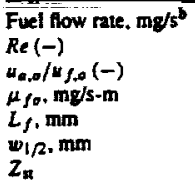 & $\begin{array}{c}0.94-3.90 \\
19-121 \\
0.22-12.03 \\
10.3 \\
21-108 \\
3.5-9.5 \\
0.0704\end{array}$ & $\begin{array}{c}153-4.08 \\
38-101 \\
0.29-6.99 \\
8.61 \\
41-108 \\
5.9-13.1 \\
0.0636\end{array}$ & $\begin{array}{c}0.74-2.71 \\
18-66 \\
0.77-32.45 \\
8.66 \\
21-75 \\
43-10.0 \\
0.0667\end{array}$ \\
\hline
\end{tabular}

Fivel por inside disneter of $6 \mathrm{~mm}$ and concentric sir part inside diemetar of $60 \mathrm{~mm}$

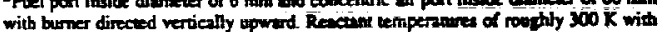
with burner disecesd verieally

Inbient pressures of $19-50 \mathrm{tP2}$. Commercial grade gased in cylinder with purides as follows: ere 
temperatures of roughly $300 \mathrm{~K}$, ambient pressures of $19-50 \mathrm{kPa}$, jelexit Reynolds numbers of 18-121, and initial aisffuel velocity ratios of 0.22-32.45

\section{Theoretical Methods}

The objective of the analysis was to develop a convenient way to heip interpret and correlate flame-shape measurements for nonbuoy. ant laminar-jet diffusion flames in coflowing air, analogous to the approach used by $L$ in et al. ${ }^{4}$ for the shapes of nonbuoyant laminar. jet diffusion flames in still air. Thus, a set of easily used equations was sought, along with recommendations for selecting the thermochermical and transpor properties appearing in these equations, as opposed to more complete methods that would require numerical sohutions on a computer. The approach used was to extend the analysis of Mahalingam et al. ${ }^{35}$ (which considers the Burke and Schumann? problem in the self-similar regime far from the source when the outer reactant stream is unbounded) 10 treat the present problem. The following description of the analysis is brief. A more detailed example of this general approach, for somewhat different initial conditions and property assumptions, is provided by Mahalingam et al. ${ }^{33}$

Except for changed ambient flow properties, the major assumptions of the present flame-shape analysis are similar to those used earlier by Lin et al. ${ }^{4}$ as follows: 1) Attention is limited to steady. axisymmetric laminar-jet difusion flames burming at constant pressure in an unbounded coflowing gas having uniform properties: 2) effects of buoyancy and associated changes of potential energy are negligible; 3) the Mach number of the flow is small so that effects of viscous dissipation and changes of kinetic energy can be ignored; 4) the flame has a large aspect ratio so that diffusion of mass (species), momentum, and energy in the streamwise direction is small; 5) for the same reasons, the solution of the governing equations can be approximated by far-field conditions where the details of initial conditions can be replaced by integral invariants of the flow for the conservation of mass, momentum. and energy: 6) all chemical reactions oceur in a chin-flame sheet with fast chemistry so that fuel and oxidant are never simultaneously present at finite concentrations; 7) the diffusivities of mass (of all species), momentum, and energy are all equal; 8) all thermophysical and transpon properties are constant throughout the flame; and 9) effects of radiation are small. The first three assumptions are justified as conditions of the present experiments. The fourth and fifth assumptions are justified for most of the present measurements that have large aspect ratios, e.g. the present measurements summarized in Table I have flame aspect ratios $2 L_{s} / w_{1 / 2}$ in the range $4-62$ and burner aspect ratios $2 L_{f} / d$ in the range $7-36$. The sixth assumption, prescribing a thin-diffusion flame sheet, has a long history of effective use to find the shapes of Iaminar-jet diffusion flames, dating back to Burke and Schumann. ${ }^{2}$ The remaining assumptions, however, are nor satisfied by laminar-jet diffusion fiames and were only adopted so that simple flame-shape formulas could be found, based on the past success of similar approximations to find the shapes of laminar-jet diffusion flames (see Refs. 4-8, 28-31, and references cited therein).

The flame configuration and notation used for the present analysis is sketched in Fig. 1. The approach is limited to self-similar behavior far from the source so that the details of source properties are not imporant; therefore, the source is represented by uniform average fuel- and air-stream velocities $u_{1.0}$ and $u_{e . .0}$. The mixture fractions (defined as the fraction of mass at a point that originated from the source fuel stream) of the source fuel and air streams are $f_{s e}=1$ and $f=0$ by definition. The enthalpy defect of the source can and $f_{a . .}=0$ by definition. The enthalpy defect of the source can conservation of energy principles are nor needed to find flame shapes under the present assumptions. The streamwise velocity defect is defined as follows:

$$
u_{d}=u_{e . \rho}-u
$$

nocing that the airstream velocity approaches $u_{c o}$ at lange $r$ for all distances from the source, based on assumption (1). In the far field, where self-similar behavior is approached, $\left|u_{d}\right| / u_{a, 0} \ll 1$ (the absolute value is used to allow for values of $u$, both larger and smaller than $u_{0,0}$ and quadratic and higher terms in $u_{d}$ can be neglected in the goveming equations. Then, under the present approximations,

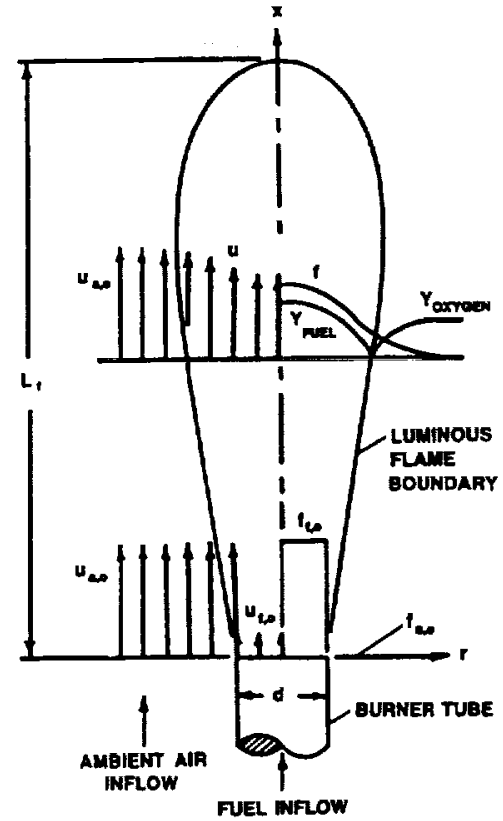

Fig. 1 Skelch of the cothoming hminar-jet diffusion tame confizurn-

the governing equation for conservation of mixnure fraction can be found in the same manner as the far-field formulation of laminar wake processes, as follows ${ }^{37}$ :

$$
\begin{gathered}
u_{\infty .0} \frac{\partial f}{\partial x}=\frac{\nu}{r} \frac{\partial}{\partial r}\left(r \frac{\partial f}{\partial r}\right) \\
r=0: \quad \frac{\partial f}{\partial r}=0, \quad r \rightarrow \infty: \quad f=0
\end{gathered}
$$

The final condition of the analysis is conservation of the flow of fuel-stream mass in the streamwise direction, which can be written as follows in far field:

$$
\int_{0}^{\infty} f r d r=\frac{d^{2} u_{f e}}{8 u_{s e}}
$$

The solution of Egs. (2-4) can be obtained using either corventional separation of variables or conversion into an ordinary differential equation by a suitable similarity transformation." The resulting expression for the mixture fraction distribution in the self-similar regime is as follows:

$$
f=u_{j .0} d^{2} \exp \left(-\eta^{2}\right\} /(16 v x)
$$

where

$$
\eta=(r / 2)\left[u_{a, o} /(v x)\right]^{t}
$$

The location of the luminous flame boundary is assumed to coincide with the location of the thin tlame sheet where the concentrations of fuel and oxident are zero (see Fig. 1) and the stoichiometric mixture fraction is reached, $f=Z_{z}$ (see Table 1 for present velues of $Z_{n}$ ). Introducing this mixture fraction into Eq. (5), for conditions along the flame axis, yields the following expression for luminous flame length:

$$
\frac{L_{f}}{d}=\frac{R e}{16 Z_{*}}
$$

The corresponding expression for flame shape, providing the flame diameter as a function of streamwise distance, is as follows:

$$
w / d=\left[\left(x / L_{f}\right)\left(u_{f . \rho} / u_{e .0}\right) \ln \left\{L_{f} / x\right] / Z_{x}\right]^{\frac{1}{2}}
$$


762

Finally, a convenient measure of the flame diameter is its value al $x / L_{j}=\frac{1}{2}$, as follows:

$$
w_{i} / d=\left[\left(u_{f . o} / u_{0.0}\right) h_{1}(2) /\left(2 Z_{k}\right)\right]^{\frac{1}{2}}
$$

Conclation of the measurements was sought in the same manner as Lin et al. 4 : The equal diffusivity approximation was relaxed by as Lin et al. The Schmide number into Eq. (7); the Schmidr number introducing the Schmidr number heynolds number were taken from and viscosity used to compute the Reynolds number the properties of air at the average of the adiabatic fiame temperalure and the ambient temperature; the correlation of flame length was improved at small aspect ratios by introducing a vinual origin al a distance $L_{\sigma}$ from the jet exit; and the flame length correlation was fine-tuned for effects of soot luminosity, etc., by introducing an (7) for the luminous flame length becomes

$$
\frac{\left(L_{f}-L_{0}\right)}{d}=\frac{C_{f} R e S c}{16 Z_{z}}
$$

whereas Eq. (8) for the luminous flame diameter becomes

$$
w / d=\left[-\zeta\left(u_{f . \alpha} / u_{a . o}\right) \ln (\zeta) / Z_{\mathrm{s}}\right]^{\frac{1}{2}}
$$

where

$$
\zeta=\frac{\left(x-L_{v}\right)}{\left(L_{f}-L_{v}\right)}
$$

Equations (9-12) disclose some interesting properties of nonbuoyant laminar-jel diffusion flames in a coflowing and unbounded but environment. First of all, the fame lenghr from Eq. (10) is is dent of the coflow velocity, which is surprixed ratio longer than in lengths in still gases from Ref. 4 are a $\left.L_{0} / d\right)$, e.z. the coefficients coflow (given similar values of $C_{f}$ and $L_{n} / d$ ). e.g. . Whe coeffeicn in the flame-length expressions of flames in coflow vary with the and $\frac{1}{16}$, respectively. Diameters of hames in contow still gases are inratio $\mu_{f o} / \mu_{o a}$; in contrast, diamelers of flames in stil gases are in dependent of reactant flow rates. "Flame-diameter properties in both coflowing and still gases, however, are only indirectly affecled by assumed transpon properties through the computation of flame-length sumed transpon propertites through the com from Eq. (10). Finally, the present analysir agres Schumann ${ }^{2}$ condiMahalingam $e t$ al. except for the presence of the virual origin and tion of $u_{f, \theta}=u_{s .0 .}$ except for the presence of the the different treatment of transpon properios. The core more exace agreement berween the self-similar prediction and the diameter of Burke and Schumann analysis for $u_{f, u}=u_{u . e}$ as the diameter of

the outer reactant stream becomes large also is

\section{Results and Discussion}

Thame Appearance Pholographs ol acetylene-, propylene- and 1, flow conditions ( $R e$ flames are illustrated in Fig. 2 f-4.2). All three flames are close to of $62-66$ and $u_{0.0} / \mu$.a shapes are relatively independent of the ambient pressure, whereas
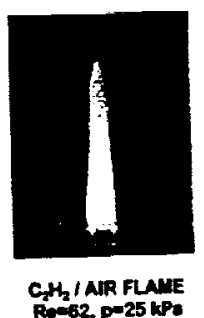

A.62, $P=25 \mathrm{kP}$

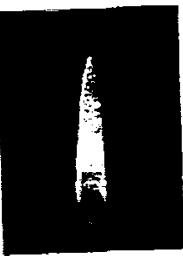

C. $\mathrm{H}_{3}$ / IAIR FLAME Remb, pese kPa

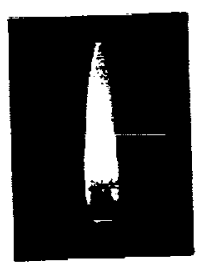
Re
CAH, IAR FLAME

Fig. 2 Pholographs of acetylene, propylene-, and 1,3-butadieneFig. 2 Pholograshs of acetyes burning in coflowing air at stmilar sirfitul velocity ratios.

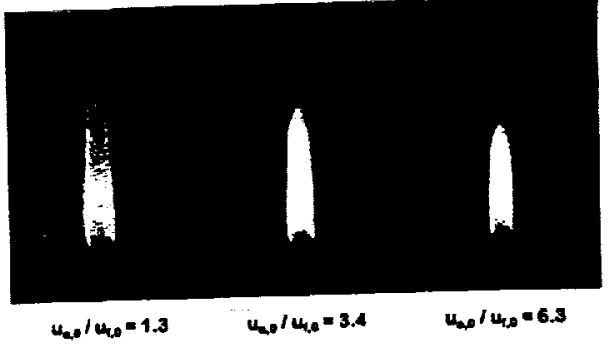

ACETMENE I AIR FLAMES, Re $=93, p=19 \mathrm{kPa}$

Fig. 3 Photographs of acetylene-fueted laminar-jet difrusion flawes Fig. 3 Photographs of acerykne-fueled laminar-jet diftus

laminar smoke-point flame lengths increase rapidly as the ambient pressure is decreased. The 1,3-butadiene flame seems somewhat pressure is decreased. The 1, mainly because of the flame attachlonger than the rest, but this is mainly because of the fiame actually, ment farther downstream from the bumer exit than the rest. Actualy, all three flames have roughly the same length, which is consistes with $\mathrm{Eq}$. (10) in view of the relatively small variaton of $Z_{\mathrm{a}}$ for these fuels (see Table 1) and past experience concerning the efiect of ap proach to the laminar smoke point on luminous flame shapes from Lin et al." Observed flame diameters are somewhan being nearly the 1.3-butadiene-fueled flame than the rest, rather than being nealy discrepancy between same as anticipated from Eq. (9). This level of discrepancy berween measured and predicted flame diameters is typical of observation over the test program and is similar to past experience for flames in still gases from Lin et al." In view of the simplicity of the flame-shape

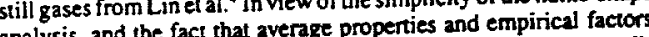
analysis, and the fact that average properties and empirical factors cannol be chosen to fit predictions and measurements of flame diameters, it is rather remarkable that

predictions are still reasonably good. Photographs of acetylene-fueled flames at given fuel jet-exic conditions and ambient pressures ( $R e$ of 93 and ambient pressure of $19 \mathrm{kPa}$ ) are illustrated in Fig. 3 for various airffuel velocity ratios. Contrary to the expeetations of Eq. (10), where luminous flame lengths are independent of airffuel velocity ratio, the flame lengths iliustrated in Fig. 3 decrease significantly as the air/fuel velocity ratio is increased. This behavior follows because luminous flame ratio is increased. This behavior follows bective to soot-free (blue) flames at lengths progressively increase relative to soot-free (blue) flames at comparable conditions as laminar smoke-point conditions are approached. For example. the luminous flame lengths at the laminar smoke point are roughly twice as long as corresponding blue flames for nonbuoyant laminar-jet diffusion flames in still air, ${ }^{4}$ and similar behavior is quite reasonable for flames in collowing laminar smokeincreasing air/fuel velocity ratios tend to increase laminar smokepoint flame lengths based on measurements of Lin and Faeth. point flame lengths $u_{a .0} / u_{f . c}=1.3$ in Fig. 3 the fiame has nearly reached its Thus, for $u_{e .0} / u_{f .0}=1.3$ in Fig. 3 the flame has forat ${ }_{0 . .0} / u_{f .0}=3.4$ laminar smoke-point flame length of $60 \mathrm{~mm}$, but for $u_{\text {... }} / u_{\text {a. }}=3.4$ the luminous flame length is only $50 \mathrm{~mm}$ compared to a laminar locity ratio, which implies a flame length between the length of a locity ratio, which implies a the length at the laminar smoke point. soot-free (blue) flame and the length at the laminar smoke point, In view of this effect of approach to the laminar smoke point, the following flame-shape measurements were obtained near laminary smoke-point-conditions, and the corresponding

\section{Flame Lengths}

Luminous fame length is defined in the following as the streamLuminous fame length is defined in the following as the stream wise distance between the bumer exit and the farthest downstream plane normal to the flame axis that contacts a luminous rength was the flame. For the present hames in coflowing air, this length was generally associated with the end of luminosity at the flame axis. For the flames of Lin et al." in still air, however, this location was either along the axis or at an annular soot layer for the closed- and open-tip flames observed near lafin 


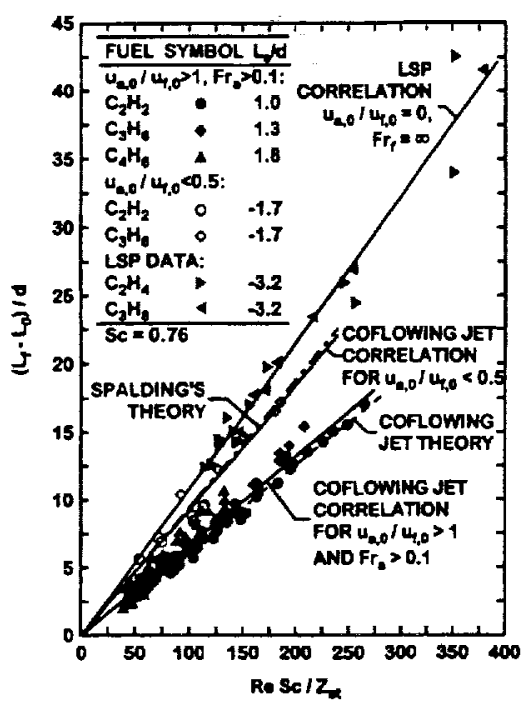

Fig. 4 Luminous flame lengths of bydrocartoon-fveted laminar.jet dif. fusion fiames burning in coflowing air: correlation and measurements of Lin et al. for $u_{e} / z_{f_{0}}=0$, predictions of the Spelding theory for $u_{a}, J_{f},=0$, correlation and messurements of the present investigation for $0.22 \leq u_{0,0} / u_{f}<0.5$, and correlation and measarements of the present investigation for coflowing jet theory.

Measured and predicted lengths of flames in cotlowing and still ait are plotted in Fig. 4. Present measurements have been divided into two groups: 1) $u_{n, \sigma} / u_{f .0}<0.5$, which roughly approximates nonbuoyant flames in still air; and 2) $u_{0.0} / u_{f .0}>1$ for $F r_{e}>0.1$, which roughly approximates nonbuoyant flames in coflowing air. All of the measurements are presented as suggested by the simplified theories of flames in collowing and still air, e.g.. Eq. (10) for tlames in coflowing air, with $\left(L_{f}-L_{o}\right) / d$ ploted as a function of $R_{e} S_{c} / Z_{\text {a }}$. Values of $Z_{z}$ used in the plots are as follows: 0.0704 for acetylene, 0.0636 for ethylene and propylene, 0.0667 for 1,3-butadiene and 0.0602 for propane. Clearly, as mentioned earlier, values of $Z_{p}$ do not vary significantly over the present test range. All other properties were obrained from Braun et al ${ }^{38}$ Values of $S c$ were based on the properties of air at the mean temperatures of the flames; these values do not change significantly over the present test range so that a mean value of $S c=0.76$ was used for plotting all of the data. The values of $\mu$ used to find Re for the plots also was based on the properties of air at the mean flame temperature. Virtual origins were selected so that fits of the measurements for various fuels and ambient flow conditions passed through the origins of the plots; the resulting values of $L_{o} / d$ are summarized in the legend of Fig. 4. Finally, plots of the various predictions for $C_{f}=1.00$ (denoted theory) and for best-fit correlations of the various measurements (denoted correlation) are also shown on the figure. For convenience, the values of $L_{\rho} / d$ and $C$ for all of the flame-length plos considered here are summarized in Table 2.

The correlation of the flames in still gases according to the simple Spalding analysis has already been discussed by Lin et al. The results illustrated in Fig. 4 for flames in still gases represent near laminar smoke-point conditions and yield an excellent correlation having relatively little scatter with $C_{f}=1.13$. As noted earlier, these luminous flame lengths for near laminar smoke-point conditions are roughly twice as long as the measurements of Sunderland et ai " for soot-free (blue) flames (Table 2). Present resules for coflowing jet flames with $u_{0.0} / u_{j .0}>1$ also yield a good correlation according to the simplified theory of Eq. (10), with $C_{f}=1.05$ in this case. Thus flame lengths for flames in still and cofowing gases have roughly the ratio discussed earlier in connection with Eq. (7), e.g.. $L_{f}$ (still air) $/ L$, (coflow) $\approx \frac{3}{2}$, with this ratio being relatively independent of $\mu_{e .0} / u_{f . o}$ and $R e$ in accord with the simplified theories. Finally present results for small coflow velocities $0.22<u_{c . o} / u_{f .0}<0.5$
Table 2 Summary of flame-length correlations

\begin{tabular}{|c|c|c|c|c|}
\hline Flame system & Source & $L_{0} / d$ & $C_{f}^{2}$ & $\sigma_{c f}$ \\
\hline $\begin{array}{l}\text { Nonbuayant laminar-jet diffusion } \\
\text { flame in collowing ais } \\
\left(\mu_{a, a} / \mu_{f, p}>1, F r_{a}>0.1 \text {. }\right. \\
\text { soct-containing flames) }\end{array}$ & $\begin{array}{l}\text { Present } \\
\text { suddy }\end{array}$ & $1.4^{\mathrm{b}}$ & 1.05 & 0.12 \\
\hline $\begin{array}{l}\text { Nonbuoyant laminar-jet diffusion } \\
\text { flame in still air }\left(u_{s, o} / \mu_{f s}=0 \text {, }\right. \\
F_{r}=\infty, \text { soot-containiag } \\
\text { flames) }\end{array}$ & Lin et al. ${ }^{4}$ & -3.2 & 1.13 & \\
\hline $\begin{array}{l}\text { Nonbuoyant laminar-jec diffusion } \\
\text { flame in slow-moving air (0.22 } \\
\leq u_{a, c,} / u_{f .0}<0.5, \text { soot-containing } \\
\text { flames) }\end{array}$ & $\begin{array}{l}\text { Present } \\
\text { study }\end{array}$ & -1.7 & 0.98 & 0.10 \\
\hline $\begin{array}{l}\text { Nonbuoyant laminar-jet diffusion } \\
\text { flame in still air (uo.o/u g., }=0 \text {, } \\
\text { Frf }=\infty \text {, soot-free, blue. } \\
\text { flames) }\end{array}$ & $\begin{array}{c}\text { Sunderland } \\
\text { et al.? }\end{array}$ & 2.7 & 0.56 & - \\
\hline
\end{tabular}

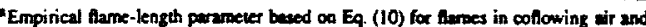
corresponding equations in Ref. 4 for themes in sill or slow-moving (u.../u fo $<0.5$ ) air.

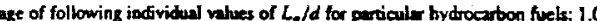
for $\mathrm{C}_{2} \mathrm{H}_{2}, 1.3$ for $\mathrm{C}_{3} \mathrm{H}_{6}$, and $\mathrm{I} .8$ for $\mathrm{C}_{4} \mathrm{H}_{6}$.

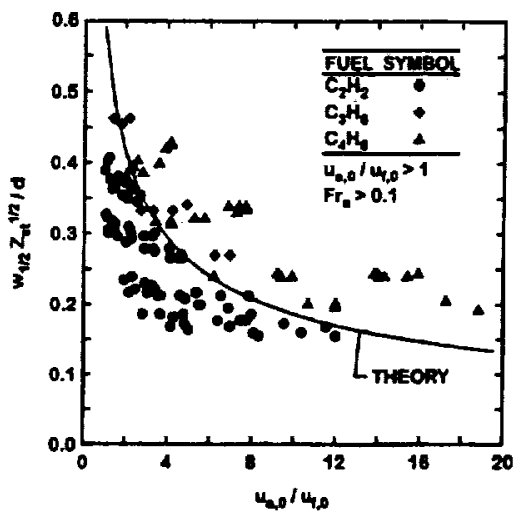

Fig. 5 Measured and predicted luminous fame diameters of bydrocarbon-fueted laminar-jet difrasion tames buming to collowtan atr at

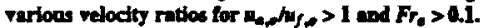

yield a reasonably good correlation in terms of the theory for fiames in still gases, e.g., $C_{f}=0.98$ from Table 2 . These results also are in reasonably good agreement with earlier measurements in still gases, with the somewhat shorter flame lengths in the presence of slow coflow being consistent with other effects of coflow seen in Fig. 4 ,

Flame Dlameters

The nomalized characteristic flame diameter $w_{1 / 2} Z_{n}^{1 / 2} / d$ for coflowing jet diffusion flames is inversely proportional to the square root of the air/fuel velocity ratio and independent of flow transpon properties, according to Eq. (9). This relationship, illustrated in Fig. 5 , is based on present measurements for $\mu_{0.0} / u_{/ .0}>1$ and $F_{r_{0}}>0.1$ along with the prodictions of Eq. (9). The measurements follow the general trend of the predictions but are rather scatrered. There also is a cendency for flame diameters to progressively increase as a function of fuel type in the order of acetyiene, propylene. and 1,3-butadiene.

Insight concerning the scatter of the measurements in Fig. 5 was sought by plotting the entire argument of $\mathrm{Eg}$. (9) as a function of normalized flame length, similar to the approach used for chanacteristic flame diameters for flames in still air by $L$ in et al ${ }^{4}$ These resules are illustrated in Fig. 6 for the same range of test conditions as Fig. 5. The scatter about the predictions progressively decreases as the nomalized fiame length increases; therefore, small-fiame aspect ratios appear to be mainly responsible for the scatter seen 


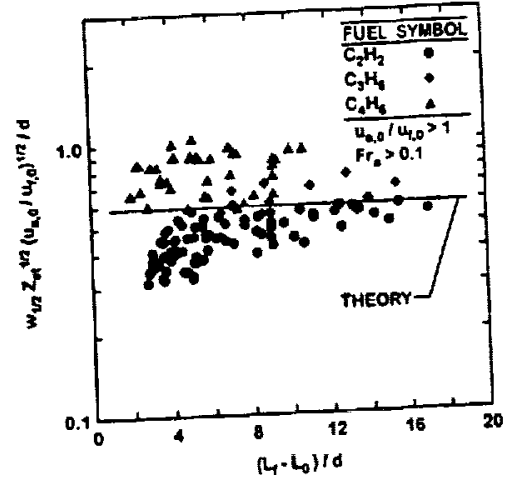

Fig. 6 Measured and predicted luminous fame diameters of bydrocorbon-fueled laminar-jet diffusion flames burning

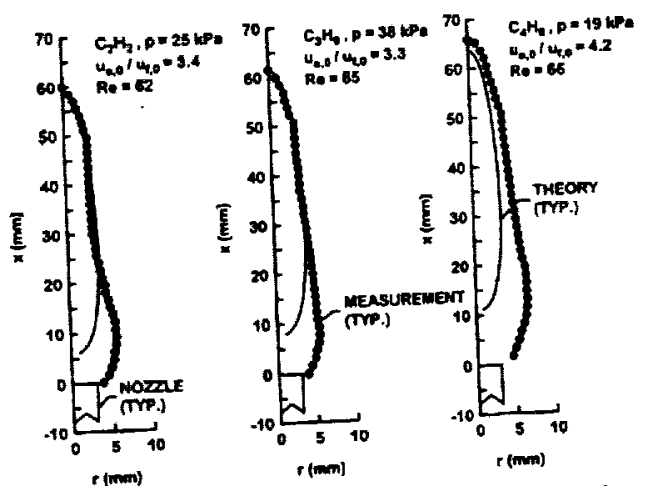

Fie. 7 Measured and predicted luminous flame shapes for acetyleneFi-7 Measured and predicted lueled laminar-jet diffusion flames burning in coftowing atr.

Fig 5. The normalized flame diameters illustrated in Fig. 6 also in Fig. 5 . The nomalized fame diam of fuel type in the order of acely. progressively increase as a function of fuel type in the order of acelylene, propylene, and 1,3-butadiene. Similar increases of nom flame diameters also were observed when changing from ethyleneto propane-fueled fiames in still gases. The reasons for these fuet

effects are not known, but fortunately the effects are not

Flame Shapes

Measured and predicted luminous flame shapes are compared as Measured and predicted luminous fimplified flame-shape analysis the final step in the evaluation of the simplined farme This comparison leading to Eqs. (9-12) for fiames in coflowing air. This comparison was carried out for relatively large fame lengths (or large aspect ratios) to reduce problems of llame-width predictions at small-fiame aspect ratios discussed in connection with Figs. 5 and 6 . Typical resulis for acetylene-, propylene-, and 1,3-butadiene-fueled hames at similar Reynolds numbers (Re of 62-66) and air foel velocity ratios $\left(u_{e .0} / u_{9.0}\right.$ of $\left.3.3-4.2\right)$ are illustrated in Fig. 7. Flame radius is plotted as a function of streamwise distance to illustrate directly the effectiveness of flame-shape predictions. The predictions clearly are quite good in the far field. A minor exception is a tendency for are quite good in the far held. A ms to underestimate the radius of the 1,3-butadiene-fueled flame in the far field, similar to the resulis discussed in connection with Fig. 6 . The far-field approximations of the analysis, however, break down near

satisfactory.

Effects of air/fuel velocity ratios and Reynolds numbers on

Effects of airfuel velocity ratios and predicled flame shapes can

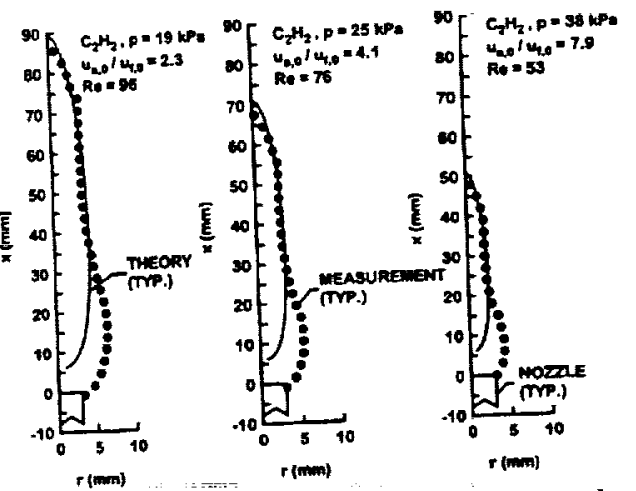

Fig. 8 Measured and predicted luminous flame shapes for acetylene-

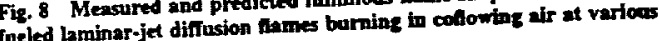
fuel jet and collow conditions.

be seen from the results plotted in Fig. 8. Conditions were selected for the plots to provide progressively shonter and narrowet flames, for the plots to provide proving $u_{0,0} / u_{g, 0}=2.3,4.1$, and 7.9 e.g., acetylene-fueled fimes having and $R e=96,76$, and 53, respectively. The approximate anations seen to provide good predictions of trends with respect to variations of airffuel velocity ratios and Reynolds numbers in the far field. Predictions near the source, however, are not satisfactory because of the failure of the far-field approximations. Mahalingam et al, observe similar trends where predictions are not satisfactory near the source when comparing their approximate self-similar analysis with the exact results of the Burke and Schumann ${ }^{2}$ analysis for the property approxim

\section{Conclusions}

The luminous fiame shapes of steady, nonbuoyant, round hydro The lumined laminar-jet diffusion hames burning in coflowing air were studied both experimentally and theoretically. Test conditions were studied both experimentene-, and 1,3-butadiene-fueled flames involved acelylene-. propylene-, and 1,3-butadiene-fueled flames having initial reactant temperatures of $300 \mathrm{~K}$, ambient pressures of $19-50 \mathrm{kPa}$, jet-exit Reynolds numbers of 18-121, and initial aistel velocity ratios of $0.22-32.45$ to yield luminous flame lengths of velocity ratios of $0.22-32.45$. The present test fames usually were close to the lami21-108 mm. The present test tames usually whe new measurements nar smoke point but were not soot eminting. The new mes shapes based were used to evaluate predictions of luminous fame shapes bal ${ }^{35}$ The on simplified analysis due to Spalding and Maws:

major conclusions of the study are as follows.

1) The present extension of the simplified analysis of nonbuoyant round laminar-jet diffusion flames in conow due to Mahalingam et al. ${ }^{35}$ provided reasonably good predictions of the luminous shapes of the present flames in the far field for $u_{+.0} / u_{f, 0}>1$ and $F r_{a}>0.1$ after appropriale selections of empirical tame-length pary for large e.g., $L_{p} / d$ and $C_{f}$. The predictions were most satisfactory where the aspect ratio flames and tended to fail near the source where the aspect ratio fames and used in the analysis were no longer valid. far-field approximations used in the aralysis were no longer validion

2) The simplified analysis of nonbuoyant laminar-jet dift aston flames in still air due to Spalding." developed by Lin e a." provided reasonably good predictions of the luminous shapes of the present flames in slow-moving coflow for $0.22 \leq \mu_{\text {a.e }} / 4 / . .<<0.5$ after appropriate selections of empirical fame-length paramelers, e.g., $L_{v} / d$ and $C_{f}$. Present values of the fiame lengths (or $C_{f}$ ) for slow colow $\left(u_{0.0} / u_{f . s}<0.5\right)$ were $15 \%$ smaller than the carliger sults of Lin et al." with no cofow because of enhanced mixing rates caused by coflow.

3) Based on present contations of the luminous flame boundaries

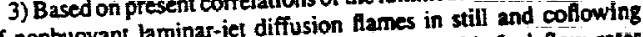
of nonbuoyant haminar-jet difusion lames in stil and collow rates air, luminous flame lengths increase linearly with fuel fow rand but are relatively independent of jet-exit diameter, pressure, and air/fuel velocity ratio (for flames in coflow). Neverticless fames in still air are roughly $50 \%$ longer than flames in significam collow $\left(u_{a,} / u_{f s}>1\right)$ at comparable conditions, with this diftereng 
relatively independent of air/fuel velocity ratio and jet-exit Reynolds number.

4) Based on present correjations of the luminous fame boundaries of nonbuoyant laminar-jet diffusion flames in still and cofowing air. characteristic luminous flame diameters vary linearly with jet-exit diameter and are relatively independent of flow physical properties and jet-exir Reynolds numbers. For flames having significant levels of coflow $\left(u_{\omega, \alpha} / u_{f o}>1\right)$ ), however, characteristic luminous flame diameters are alsa inversely proporional to the square root of $u_{u . o} / u_{\rho, v}$. Thus, large aspect ratio flames can best be achieved using small injector diameters, large injector Reynolds numbers, and large air/fuel velocity ratios, subject to laminar smoke-point limitations if nonsooting flames are desired

5) Progressive increases of luminous flame lengths at comparable conditions were observed as the laminar smoke point was approached for nonbuoyant laminar-jel diffusion flames in coflowing air. This behavior was similar to the observations of Lin et al. ${ }^{4}$ that the luminous lengths of nonbuoyant laminar-jet diffusion flames in still air were roughly twice as long at near laminar smoke-point conditions as sool-free (blue) flames at comparable conditions. Whether quantitative effects of approach to the laminar smoke point are the same for flames in coflowing and still air, however, still must be established.

Finally, we recommend that the correlation of flame shapes for nonbuoyant laminar-jet diffusion flames in coflowing air [Egs. $(9-12)]$ be used with caution outside the present test range and until the results are definitively confirmed for long-term microgravity conditions where the intrusion of effects of transient flame development and buoyancy are absent. In paricular, past observations of the shapes of steady nonbuoyant laminar-jet diffusion flames in still gases based on space-based observations in microgravity generally have been found to differ from earlier measurements obtained using ground-based facilities due to effects of transient flame development and disturbances due to buoyancy. The present conclusions concerning effects of burner diameter follow from the simplified theory; experimental evaluation of these trends is needed.

\section{Acknowledgments}

This research was supported by NASA Grants NAG3-1245 and NAG3-2048 under the technical management of David L. Uman of the NASA Lewis Research Center and by Office of Naval Research Grant N00016-95-0238 under the technical management of Gabriel D. Roy

\section{References}

'Bilger. R. W.. "Reaction Rales in Diffusion Fames," Combustion and Flame, Vol. 30, No. 3. 1977. pp. 277-284.

${ }^{2}$ Burke, S. P., and Schumann. T. E. W. "Diffusion Flames," Indwerrial and Engineering Chemistry. Vol. 20. No. 10. 1928. pp. 998-1004.

${ }^{3} \mathrm{Law}$, C. K., and Faeth, G. M. "Opponunities and Challenges of Combustion in Microgravity." Progress in Energy and Combustion Sciences. Vol. bustion in Microgravity." Pro. 1.1994, pp. 65-113.

'Lin, K.C.. Faeth, G. M.. Sunderiand, P. B., Uraan, D. L. and Yuan, Z-G." "Shapes of Nonbuoyant Round Luminous Hydrocarton/Air Laminar Jet Diffusion Flames," Cambussion and Flame. Yol. 116. No. 3, 1999, pp. $415-431$.

SSpalding, D. B., Combustion and Mass Transfer. Pergamon, New York 1979. pp. 185-195.

370 .

Kuo, K. K., Principles of Combustion, Wiley, New York, 1986, pp. 360

'Urtan, D. L., Yuan, Z.G., Sunderland, P. B., Linveris, G. T., Voss, J. E., Lin. K.-C., Dai, Z., Sun, K., and Freth, G. M.. "Sirscture and Soor Properties of Nonbuoyant Ethylene/Air Laminar Jet Diffusion Flames," AIAM Joumal Vol. 36. No. 8, 1998, pp. 1346-1360.

${ }^{8}$ Sunderiand, P. B., Mendelson, B. J., Yuan, Z.G. and Uran D. L "Shapes of Buoyant and Nonbuoyant Laminar jet Diffusion Flames." Com bustion and Flame. Vol. I16, No. 3, 1999, pp. 376-386.

${ }^{9}$ Sunderland, P. B.. Morrazavi, S. Freth, G. M., and Uitan. D. L., "Lam inar Smoke Points of Nonbuoyant Jet Diffusion Flames," Combustion and Flame, Vol. 96. No. 1, 1994, pp. 97-103.

${ }^{10}$ Schug. K. P., Manheimer-Timnat. Y., Yaccarino, P., and Glassman. I.. "Sooting Behavior of Gaseous Hydrocarton Difusion Panes and the lnfo ence of Additives," Combustion Science and Technology. Vol. 22, No. 5/6, 1980, pp. 235-250.

"Gomez. A.. Sidebotham, G., and Glassman, I.. "Sooting Behavior in Temperalure-Conurolled Laminar Diffusion Flames." Combustion and
12 Mitchell, R. E., Sarofim, A. F., and Clomberg, L. A., "Experimental and Numerical Investigation of Confined Laminar Diffusion Flames" Combus. lion and Flame, Vol. 37. No. 3, 1980, pp. 227-244.

${ }^{13}$ Saito. K., Williams, F. A., and Gordon. A. S., "Strueture of Laminas Coflow Methane-Air Diffusion Flames," Joumal of Heat Transfer, Vol. 108, No. 3, 1986, pp. 640-648.

"Saito, K., Williams, F. A., and Gordon, A. S., "Effects of Oxygen on Soot Formation in Diffusion Flames." Combustion Science and Technology. Vol. 47, No. 3/4, 1986. pp. 117-138.

is Sunderland, P. B., "Soot Nucleation and Growth in Weakly Buoyant Laminas Jet Diffusion Flames," Ph.D. Dissertation, Dept. of Aero space Engineering. Univ. of Michigan. Ann Arbor, MI. June 1995.

${ }^{16}$ Sunderland, P. B., Köylu, U. O., and Faeth, G. M., "Sool Formation in Weakly Buoyant Acetylene-Fueled Laminar Jet Diffusion Flames Buming in Air," Combustion and Flame, Vol. 100, No, 12, 1995, pp. 310-322.

${ }^{17}$ Lin. K.-C., "Hydrodynamic Effects on Soot Formation in Laminar Hydrocartion-Fueled Diffusion Flames," Ph.D. Dissertation. Depl. of Aerospace Engineering, Univ, of Miehigan, Ann Abor, MI, June 1996.

${ }^{18}$ Lin, K.-C., Sunderiand, P. B., and Faeth, G. M., "Soot Nucleation and Growth in Acetylene/Air Laminar Coflowing Jet Diffusion Flames," Combustion and Flame, Vol. 104, No. 3, 1996, pp. 369-375.

${ }^{19} \mathrm{Lin}, \mathrm{K} .-\mathrm{C}$., and Faeth. G. M. "Hydrodynamic Suppression of Soor Emissions in Laminar Diffusion Fames," Joumal of Propulsion and Power. Vol. 12. No. 1. 1996. pp. 10-17.

${ }^{20}$ Cochran. T. H., and Masica, W. J., "An Investigation of Gravity Effects on Laminar Gas Jet Diffusion Flames," Thirteenth Symposium (ln rernational) on Combustion, Combustion Inst. Pitsburgh, PA, 1970, pp. B21-829.

${ }^{21}$ Haggard, J. B., Jr., and Cochran, T. H. "Stable Hydrocarbon Diffusion Flames in a Weightless Environment," Combustion Science and Technology. Vol. 5, No. 4-6. 1972, pp. 291-298.

${ }^{22}$ Edelman, R. B., Fortune, O. F., Weilersiein, G. Cochran. T. H., and Haggard, J. B., Je., "An Analytical and Experimental Investigation of Gravity Effects upon Laminar Gas Jet-Diffusion Flames," Fourneenth Symposium (Iniernational) on Combustion, Combustion Inst., Pittsburgh, PA., 1972, pp. 399.412.

${ }^{23}$ Edelman, R. B., and Bahadori, M. Y., "Efreets of Buoyancy on Gas-Jet Diffusion Flames: Experiment and Theory," Acta Astronautica, Vol. 13, No. I1/12. 1986, pp. $681-688$.

${ }^{24}$ Bahadori, M. Y.. Edelman, R. B.. Stocker, D. P., and Olson, S. L., "Jgnition and Behavior of Laminar Gas-Jet Diffusion Flames in Microgravity." AlAA Joumal, Vol, 28, No. 2, 1990. pp. 236-244.

${ }^{23}$ Bahadori, M. Y. Stocker, D. P., and Edelman, R. B. "Effects of Pressure on Microgravity Hydrocarbon Diffusion Plames," AlAÄ Paper 90-0651.Jan. 1990.

${ }^{26}$ Bahadori, M. Y., Edelman, R. B., Solos, R. G., and Stocker, D. P. "Radiation from Gas-Jet Diffusion Flames in Microgravity Environments," AlAA Paper 91-0719, Jan. 1991.

${ }^{27}$ Bahadori, M. Y., Edeiman, R. B., Stocker, D. P., Soros, R. G., and Vaughan. D. F., "Effects of Oxygen Concentration on Radiative Loss from Normal-Grevity and Microgravity Methane Diffusion Flames," AIAA Paper 92-0243, Jan. 1992

${ }^{2}$ lost, W., Explosion and Combustion Processes in Gases. McGrow-Hill. New York, 1946, Chap. 1

${ }^{29}$ Roper, F. G., "Prediction of Laminar Jet Diffusion Flames; Part l: Theoretical Model," Combustion and Flame, Vol . 29. No. 3, 1977, po. 219-226.

${ }^{30}$ Roper. F. G. Smith. C. and Cunningham, A. C.. "The Predictions of Laminar Jet Diffusion Flame Sizes: Part II Experimental Verification. " Combustion and Flame, Vol. 29, No. 3. 1977, pp. 227-234.

${ }^{31} \mathrm{Klajn}, \mathrm{M}$., and Oppenheim, A. K. "Influence of Exothermicity on the Shape of a Diffusion Flame," Nineseenth Symposium (Intemational) on Combustion. Combustion Inst., Pittsburgh, PA. 1982, pp. 223-235.

${ }^{12}$ Li. S. C., Gordon, A. S., and Williams, F. A., "A Simplified Method for the Computation of Burke-Schumann Flames in Infinite Almospheres" Combustion Science and Techrology, Vol. 104, No. 1-3. 1995, pp. 75-91.

${ }^{33}$ Ban, H., Venkatesh, S., and Saito, K "Convection-Diffusion Controlled Laminar Micro Flames," Joumal of Hear Transfer. Vol. 116. No. 4. 1994. pp. 954-959.

${ }^{3}$ Williams, F. A., Combustion Theory, 2 nd ed., Benjanin Cummings Publishing. Menlo Park, CA, 1985, pp. 38-47.

${ }^{35}$ Mahalingam, S., Ferziger, J. H., and Caniwell. B. J., "Self-Similar Diffusion Flames," Combustion and Flame, Vol. 82, No. 2, 1990, pp. 231-234.

${ }^{36}$ Hamins, A., Gordon, A. S., Saito, K., and Seshadri, K. "Acerone Impurity in Acerylene from Tanks," Combustion Science and Technolocy. Vol. 45. No. 5. 1986, pp. 309-310.

${ }^{37}$ Schlichting. H.. Boundary Layer Theory, 4th ed., McGnw-Hill, New York.1960, pp. 160-164

34 Braun, W. G.. Danner, R. P., and Dauben, T. E., Technical Date BookPetroleum Refining. 3rd ed. American Petroleum Inst.. Washington. DC 1976. Chaps. 11 and 13.

S. K. Aggarwal 
